\title{
Effects of cigarette smoking on intraocular pressure and vision
}

\author{
ROY J. SHEPHARD, ELLENOR PONSFORD, P. K. BASU, AND \\ ROBERT LABARRE \\ From the Department of Preventive Medicine and Biostatistics, University of Toronto, \\ the Department of Ophthalmology, University of Toronto, and the Computer Centre, University of Quebec \\ at Trois Rivières
}

SUMMARY In a survey of 426 patients of Toronto ophthalmologists the correlations of reported smoking habits with (1) intraocular pressure and (2) visual acuity were examined. Average tonometer readings were closely similar in smokers, ex-smokers, and non-smokers, and multıple regression analysis showed similar age coefficients for the 3 categories. However, in women (but not in men) there was also a significant coefficient related to total cigarette exposure (puff-pack-years). It is suggested that this was due to recent smoking rather than a permanent effect on tonometer pressures, pointing the need to standardise this aspect of ocular pressure measurements. Visual acuity showed similar age coefficients in smokers, ex-smokers, and non-smokers, with no independent effect of exposure to cigarette smoke.

Previous papers from our laboratories have noted direct and 'passive' effects of cigarette smoke exposure on the eye (Sebben et al., 1977; Basu et al., 1977; Shephard et al., 1978). Reactions include irritation, with an immediate disturbance of vision (Shephard et al., 1978), lacrimation (Shephard et al., 1978), and a shortening of the time to break up of the tear film (Basu et al., 1977). In other contexts it has been widely accepted that exposure to irritant gases can cause open-angle glaucoma (Duke-Elder and Jay, 1969), with both acute and more long-term increases of intraocular pressure (Ballantyne and Swanston, 1977; Ballantyne et al., 1977).

The situation with regard to cigarette smoking is less clearly established. Mehra et al. (1976) reported an acute rise of intraocular pressure $>0.67 \mathrm{kPa}^{*}$ $(5 \mathrm{mmHg})$ in $11.4 \%$ of normal subjects and $37.1 \%$ of patients with primary glaucoma; measurements were made within 5 minutes of the last puff on a cigarette, and normal pressures were restored within 15 to 30 minutes. On the other hand Bahna and Bjerkedal (1948) found no relationship between

*The kilopascal is the unit of pressure now recommended by the International Committee on the standardisation of units.

Address for reprints: Professor Roy J. Shephard, Department of Preventive Medicine and Biostatistics, University of Toronto, Toronto M5S 1A8, Canada tonometer readings and reported smoking habits. Morgan and Drance (1975) also observed no association between smoking habits and the development of chronic open-angle glaucoma with associated optic disc change and field defects. However, in their study what was described as uncomplicated chronic glaucoma (ocular tension $>2.79 \mathrm{kPa}$, $21 \mathrm{mmHg}$ ) was significantly associated with a high current cigarette consumption (more than 20 cigarettes a day).

The present report further examines the relationship of smoking habits to (1) intraocular pressures and (2) corrected vision.

\section{Methods}

The survey was conducted in co-operation with a number of ophthalmologists in Toronto who were measuring intraocular pressures as part of routine examinations of the visual system. A nurse attended the physicians' offices, soliciting volunteers, who completed a questionnaire on their smoking habits and visual reactions to cigarette smoke (Shephard et al., 1978); they also agreed to release the data resulting from their ophthalmological examination.

A total of $\mathbf{4 2 6}$ adults over the age of 20 years were seen. After a standard clinical ophthalmological examination intraocular pressures were recorded by standard tonometric procedures, while visual acuity 
Table 1 Reported current cigarette consumption of smokers, by age and sex

\begin{tabular}{|c|c|c|c|c|c|c|c|c|}
\hline \multirow{2}{*}{$\begin{array}{l}\text { Number of } \\
\text { cigarettes } \\
\text { per day }\end{array}$} & \multicolumn{4}{|l|}{ Men } & \multicolumn{4}{|c|}{ Women } \\
\hline & $\begin{array}{l}21-40 \\
\text { years } \\
(\%)\end{array}$ & $\begin{array}{l}41-60 \\
\text { years } \\
(\%)\end{array}$ & $\begin{array}{l}>60 \\
\text { years } \\
(\%)\end{array}$ & $\begin{array}{l}\text { All } \\
\text { ages } \\
(\%)\end{array}$ & $\begin{array}{l}21-40 \\
\text { years } \\
(\%)\end{array}$ & $\begin{array}{l}41-60 \\
\text { years } \\
(\%)\end{array}$ & $\begin{array}{l}>60 \\
\text { years } \\
(\%)\end{array}$ & $\begin{array}{l}\text { All } \\
\text { ages } \\
(\%)\end{array}$ \\
\hline $1-10$ & $21 \cdot 1$ & $28 \cdot 6$ & $28 \cdot 6$ & $26 \cdot 2$ & $16 \cdot 7$ & $25 \cdot 0$ & $39 \cdot 4$ & $28 \cdot 7$ \\
\hline $11-20$ & $31 \cdot 6$ & $19 \cdot 0$ & $38 \cdot 1$ & $29 \cdot 5$ & $38 \cdot 9$ & $27 \cdot 9$ & $21 \cdot 2$ & $27 \cdot 6$ \\
\hline $21-40$ & $42 \cdot 1$ & $42 \cdot 9$ & $33 \cdot 3$ & $39 \cdot 3$ & $44 \cdot 4$ & $41 \cdot 7$ & $36 \cdot 4$ & $40 \cdot 2$ \\
\hline 41 or more & $5 \cdot 3$ & $9 \cdot 5$ & - & 4.9 & - & $5 \cdot 6$ & $3 \cdot 0$ & $3 \cdot 4$ \\
\hline
\end{tabular}

Table 2 Reported age of starting to smoke in relation to current consumption and to sex

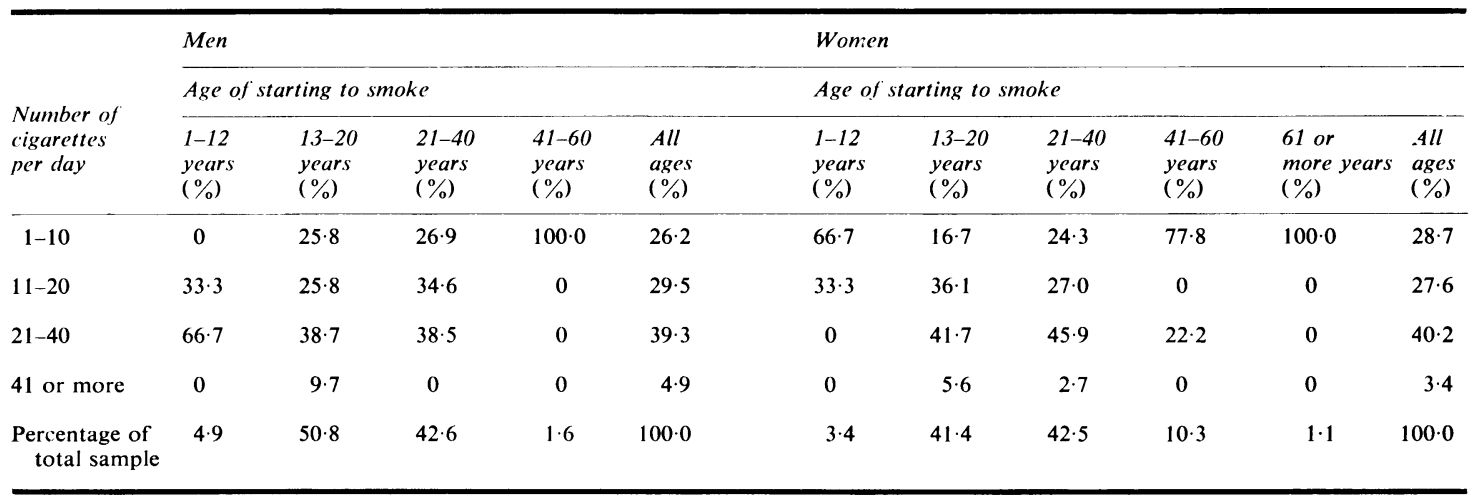

(corrected and uncorrected) was assessed by Snellen test charts.

\section{Results}

SUBJECTS AND SMOKING HABITS

Perhaps because the clinics were held during the daytime the sample included more women (269) than men $(157) ; 89$ subjects were aged 21 to 40 years, 167 were 41 to 60 years, and 170 were over the age of 60 years.

The proportion of current smokers $(38.9 \%$ of the men, $32.3 \%$ of the women) was slightly lower than in previous Toronto (Shephard and LaBarre, 1978) and Provincial (Non-Medical Use of Drugs Directorate, 1976) samples, with 148 smokers (61 men, 87 women,) 96 ex-smokers (50 men, 46 women), and 182 non-smokers (46 men, 136 women). The pattern of current cigarette usage (Table 1) was much as expected; probably for financial reasons there were somewhat fewer heavy smokers (more than 20 cigarettes a day) in people aged over 60 years.

The largest number of subjects had begun to smoke between 13 and 20 years of age (Table 2), and this group seemed particularly vulnerable to a very high (more than 40 cigarettes a day) current consumption. Total cigarette exposure was calculated in terms of pack years and cigarette-puff years (puffs per cigarette $\times$ average daily consumption $\times$ $365 \times$ years of smoking). The men tended to take more puffs per cigarette than the women (Table 3 ), average lifetime scores for the 2 groups being 2.45 and 1.46 million puffs respectively.

\section{TONOMETRIC PRESSURES}

Tonometric pressures conformed closely with previously reported data from other laboratories (Table 4). Values varied little with the reported cigarette consumption. If $2.8 \mathrm{kPa}(21 \mathrm{mmHg})$ is taken as an upper limit of normality, this pressure was exceeded by 8 of 150 readings on smokers, 5 of 98 readings on ex-smokers, and 12 of 185 readings on non-smokers. However, in most of the smokers the excess pressure was small. Thus, if the limit of normality were extended to $2 \cdot 1 \mathrm{kPa}(22 \mathrm{mmHg})$, 2 of 150 smokers, 3 of 98 ex-smokers, and 10 of 185 non-smokers would have been regarded as abnormal.

When mean values were considered, there was a 
suggestion of an increment of pressure in the heavy smokers, particularly the women. This trend was supported when data were classified in terms of the number of puffs per cigarette (Table 5).

To test the significance of this tendency, multiple regression equations were established relating tonometer pressure, $\mathrm{T}$ (mean of right and left, $\mathrm{mmHg}$ ), to age, A (years), and total cigarette

Table 3 Puffs per cigarette and total cigarette exposure (puffs per lifetime)

\begin{tabular}{|c|c|c|c|}
\hline \multicolumn{2}{|c|}{ Puffs per cigarette } & \multirow{2}{*}{$\begin{array}{l}\text { Percent of } \\
\text { sample }\end{array}$} & \multirow{2}{*}{$\begin{array}{l}\begin{array}{l}\text { Total cigarette exposure } \\
\text { (million puffs per lifetime }\end{array} \\
0.457\end{array}$} \\
\hline Men & $1-5$ & & \\
\hline & $6-10$ & $42 \cdot 6$ & 1.984 \\
\hline & $11-15$ & $31 \cdot 1$ & 1.893 \\
\hline & $16-20$ & $19 \cdot 7$ & $4 \cdot 632$ \\
\hline & $>20$ & $1 \cdot 7$ & $5 \cdot 183$ \\
\hline \multirow[t]{5}{*}{ Women } & $1-5$ & $13 \cdot 8$ & 0.528 \\
\hline & $6-10$ & $47 \cdot 1$ & 0.909 \\
\hline & $11-15$ & $23 \cdot 0$ & 1.851 \\
\hline & $16-20$ & 14.9 & $3 \cdot 112$ \\
\hline & $>20$ & $1 \cdot 2$ & $6 \cdot 027$ \\
\hline \multirow[t]{5}{*}{ Both sexes } & $1-5$ & $10 \cdot 1$ & 0.514 \\
\hline & $6-10$ & $45 \cdot 3$ & $1 \cdot 327$ \\
\hline & $11-15$ & $26 \cdot 4$ & 1.871 \\
\hline & $16-20$ & $16 \cdot 9$ & $3 \cdot 841$ \\
\hline & $>20$ & $1 \cdot 3$ & 5.605 \\
\hline
\end{tabular}

Table 5 Intraocular pressure and puffs per cigarette. Mean $\pm S D$

\begin{tabular}{|c|c|c|c|c|}
\hline \multirow{3}{*}{ Puffs per cigarette } & \multicolumn{3}{|c|}{ Intraocular pressure } & \\
\hline & \multicolumn{2}{|l|}{ Right eye } & \multicolumn{2}{|l|}{ Left eye } \\
\hline & $(m m H g)$ & $(k P a)$ & $(m m H g)$ & $(k P a)$ \\
\hline $1-5 \quad(n=15)$ & $14 \cdot 7 \pm 4 \cdot 2$ & 1.96 & $15 \cdot 5 \pm 3 \cdot 9$ & $2 \cdot 06$ \\
\hline $6-10(n=64)$ & $14 \cdot 7 \pm 3 \cdot 4$ & 1.96 & $14 \cdot 7 \pm 3 \cdot 7$ & 1.96 \\
\hline $11-15(n=36)$ & $15 \cdot 0 \pm 4 \cdot 4$ & $2 \cdot 00$ & $15 \cdot 4-4 \cdot 3$ & $2 \cdot 05$ \\
\hline $16-20(n=23)$ & $16 \cdot 9 \pm 3 \cdot 1$ & $2 \cdot 25$ & $16 \cdot 8: 2 \cdot 7$ & $2 \cdot 23$ \\
\hline $21(n=2)$ & $17 \cdot 3 \pm 1 \cdot 8$ & $2 \cdot 30$ & $17 \cdot 3 \sqsubset 1 \cdot 8$ & $2 \cdot 30$ \\
\hline
\end{tabular}

exposure (pack years (PY) or puff-pack years (PPY); the significance of the 2 independent variables is shown in parenthesis:

Men and women

$\mathrm{T}=0.076(\mathrm{~A})-0.0013(\mathrm{PY})+11.46(\mathrm{P}<0.005, \mathrm{NS})$

$\mathrm{T}=0.069(\mathrm{~A})-0.0024(\mathrm{PPY})+11.58(\mathrm{P}<0.008, \mathrm{NS})$

Men

$\mathrm{T}=0.141(\mathrm{~A})-0.0352(\mathrm{PY})+9.61(\mathrm{P}<0.009, \mathrm{NS})$

$\mathrm{T}=0.128(\mathrm{~A})-0.0108(\mathrm{PPY})+10.00(\mathrm{P}<0.018, \mathrm{NS})$

Women

$\mathrm{T}=0.071(\mathrm{~A})+0.0268(\mathrm{PY})+10.83(\mathrm{P}<0.031, \mathrm{NS})$

$\mathrm{T}=0.075(\mathrm{~A})+0.0106(\mathrm{PPY})+10.58(\mathrm{P}<0.021,0.040)$

The age effect was highly significant in all of these analyses, but after allowance for this variable the effects of cigarette exposure were relatively small, the one significant coefficient $(P<0.040)$ being for puff-pack years in the women.

The age coefficients for non-smokers $(0.075 \pm$

Table 4 Mean tonometer pressures and cigarette smoking. Mean $\rfloor S D$

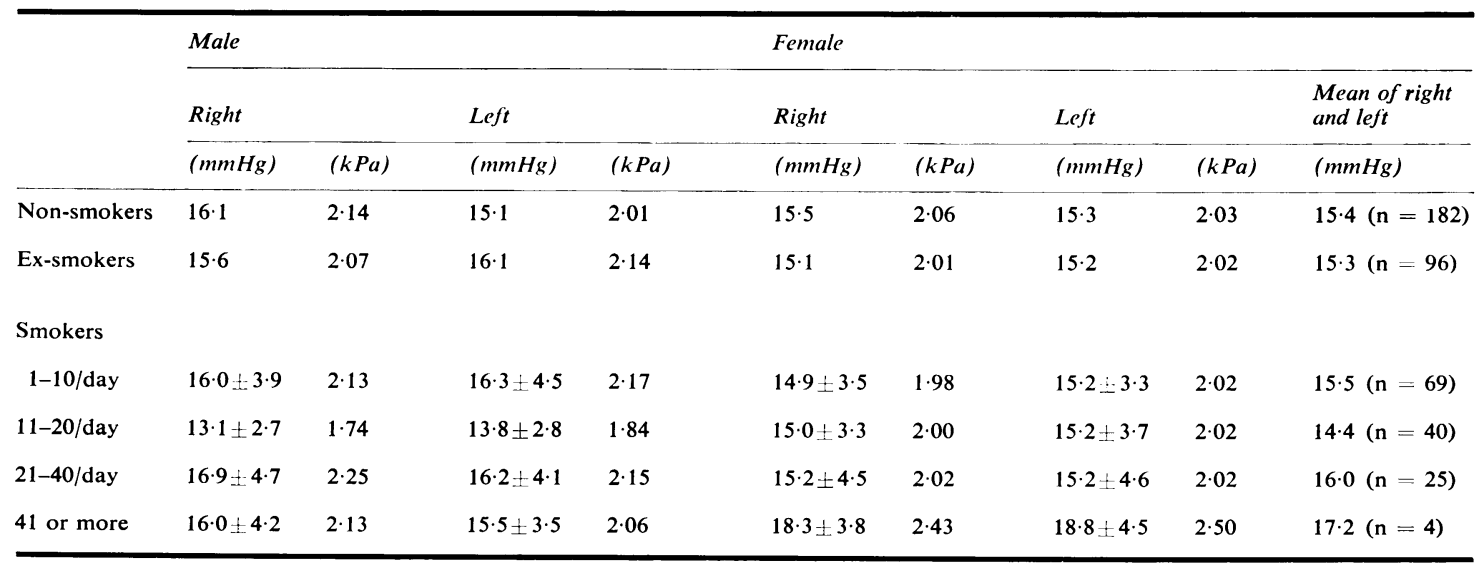


Table 6 Visual acuity and cigarette consumption (\% poor)*

\begin{tabular}{|c|c|c|c|c|c|c|c|c|c|c|}
\hline & \multicolumn{5}{|c|}{ Uncorrected } & \multicolumn{5}{|c|}{ Corrected } \\
\hline & \multicolumn{2}{|l|}{ Male } & \multicolumn{2}{|c|}{ Female } & \multirow{2}{*}{$\begin{array}{l}\begin{array}{l}\text { All subjects } \\
\text { mean of }\end{array} \\
\text { Right and left }\end{array}$} & \multicolumn{2}{|l|}{ Male } & \multicolumn{2}{|c|}{ Female } & \multirow{2}{*}{$\begin{array}{l}\begin{array}{l}\text { All subjects } \\
\text { mean of }\end{array} \\
\text { Right and left }\end{array}$} \\
\hline & Right & Left & Right & Left & & Right & Left & Right & Left & \\
\hline Non-smokers & $70 \cdot 6$ & $80 \cdot 4$ & $73 \cdot 5$ & $54 \cdot 3$ & $66 \cdot 8$ & $54 \cdot 3$ & $54 \cdot 3$ & $54 \cdot 4$ & $53 \cdot 7$ & $54 \cdot 2(n=182)$ \\
\hline Ex-smokers & $65 \cdot 2$ & $63 \cdot 0$ & $80 \cdot 0$ & $80 \cdot 0$ & $76 \cdot 0$ & $50 \cdot 0$ & $50 \cdot 0$ & $40 \cdot 0$ & $42 \cdot 0$ & $43 \cdot 3(n=96)$ \\
\hline $\begin{array}{l}\text { Smokers } \\
1-10 / \text { day }\end{array}$ & 88.9 & $81 \cdot 5$ & $83 \cdot 0$ & $85 \cdot 1$ & $84 \cdot 5$ & $33 \cdot 3$ & $25 \cdot 9$ & $34 \cdot 0$ & $40 \cdot 4$ & $34 \cdot 4(n=67)$ \\
\hline 11-20/day & $93 \cdot 8$ & $75 \cdot 0$ & $56 \cdot 0$ & $56 \cdot 0$ & $67 \cdot 1$ & $31 \cdot 3$ & $37 \cdot 5$ & $52 \cdot 0$ & 56.0 & $46.4(n=40)$ \\
\hline 21-40/day & $81 \cdot 3$ & $81 \cdot 3$ & $61 \cdot 5$ & $69 \cdot 2$ & $74 \cdot 2$ & $43 \cdot 8$ & $62 \cdot 5$ & $30 \cdot 8$ & $46 \cdot 2$ & $46 \cdot 6(n=25)$ \\
\hline$>40$ & $100 \cdot 0$ & $100 \cdot 0$ & $100 \cdot 0$ & $100 \cdot 0$ & $100 \cdot 0$ & $50 \cdot 0$ & $50 \cdot 0$ & $50 \cdot 0$ & $50 \cdot 0$ & $50 \cdot 0(n=4)$ \\
\hline
\end{tabular}

*Poor is here defined as an acuity $<10 / 20$

Table 7 Visual acuity and puffs per cigarette (\% of sample in each category)

\begin{tabular}{|c|c|c|c|c|c|c|c|}
\hline \multirow{2}{*}{ Vision } & & \multicolumn{6}{|c|}{ Puffs per cigarette } \\
\hline & & $1-5$ & $6-10$ & $11-15$ & $16-20$ & $>21$ & All categories \\
\hline \multicolumn{8}{|l|}{ Uncorrected } \\
\hline \multirow[t]{2}{*}{ Right } & Poor* & $9 \cdot 3$ & $41 \cdot 5$ & $30 \cdot 5$ & 15.9 & $1 \cdot 7$ & $78.7(n=118)$ \\
\hline & Normal & 12.5 & $56 \cdot 5$ & $15 \cdot 6$ & $15 \cdot 6$ & 0 & $21 \cdot 3(n=32)$ \\
\hline \multirow[t]{2}{*}{ Left } & Poor & $8 \cdot 7$ & $43 \cdot 5$ & $31 \cdot 3$ & $15 \cdot 7$ & 0.9 & $76.7(n=115)$ \\
\hline & Normal & $14 \cdot 3$ & $48 \cdot 6$ & $14 \cdot 3$ & $20 \cdot 0$ & $2 \cdot 9$ & $23 \cdot 3(n=35)$ \\
\hline \multirow[t]{2}{*}{$\begin{array}{l}\text { Average } \\
\text { right and left }\end{array}$} & Poor & $9 \cdot 0$ & 42.5 & $30 \cdot 9$ & $16 \cdot 3$ & 1.4 & $77 \cdot 7$ \\
\hline & Normal & $13 \cdot 4$ & $52 \cdot 6$ & $15 \cdot 0$ & $17 \cdot 8$ & 1.5 & $22 \cdot 3$ \\
\hline \multirow[t]{2}{*}{$\begin{array}{l}\text { Corrected } \\
\text { Right }\end{array}$} & Poor & $12 \cdot 1$ & $44 \cdot 8$ & $20 \cdot 7$ & $20 \cdot 7$ & $1 \cdot 7$ & $38.7(n=58)$ \\
\hline & Normal & $8 \cdot 7$ & $44 \cdot 6$ & $31 \cdot 5$ & $14 \cdot 1$ & $1 \cdot 1$ & $61 \cdot 3(n=92)$ \\
\hline \multirow[t]{2}{*}{ Left } & Poor & $12 \cdot 1$ & $50 \cdot 0$ & $16 \cdot 7$ & $18 \cdot 2$ & $3 \cdot 0$ & $44 \cdot 0(n=66)$ \\
\hline & Normal & $8 \cdot 3$ & $40 \cdot 5$ & $35 \cdot 7$ & $15 \cdot 5$ & $\mathbf{0}$ & $56 \cdot 0(n=84)$ \\
\hline \multirow[t]{2}{*}{$\begin{array}{l}\text { Average } \\
\text { right and left }\end{array}$} & Poor & $12 \cdot 1$ & $47 \cdot 9$ & $18 \cdot 7$ & $19 \cdot 5$ & $2 \cdot 4$ & $41 \cdot 4$ \\
\hline & Normal & 8.5 & $42 \cdot 6$ & $33 \cdot 6$ & $14 \cdot 8$ & 0.6 & $58 \cdot 7$ \\
\hline
\end{tabular}

*Poor is here defined as an acuity $<10 / 20$

$0.027)$ and ex-smokers $(0.115 \pm 0.034)$ did not differ significantly from those for smokers.

VISUAL ACUITY

In view of the nature of our sample, most subjects had some impairment of visual acuity. Nevertheless, for purposes of statistical comparison it was possible to distinguish 2 categories - mild impairment (vision $>10 / 20$ ) and 'poor' vision (acuity $<10 / 20$ ). On this criterion the uncorrected vision of the smokers (78.1\% of the sample with 'poor' vision) was possibly $(0.2>\mathbf{P}>0.1)$ a little poorer than that of the non-smokers $(66.8 \%$ of the sample with 'poor' vision). The corrected vision was poorer in the heavy than the light smokers (Table 6) but was at least equally poor in the non-smokers.

The gradient of visual acuity with cigarette exposure was also seen when results were classified 
by puff frequency (Table 7). Those taking more than 10 puffs per cigarette included $48.5 \%$ of those with poor uncorrected vision but only $34.0 \%$ of those with normal vision. In terms of corrected vision the dividing line of 10 puffs per cigarette was less satisfactory, $40.0 \%$ of those with poor vision and $48.9 \%$ of those with normal vision exceeding this exposure. However, among those taking more than 15 puffs per cigarette were $21 \cdot 3 \%$ of those with poor vision and only $15.3 \%$ of those with good vision.

Expressing the corrected visual acuity in digital terms $(20 / 20=1 \cdot 0)^{*}$, multiple regression equations were computed as follows:

$$
\begin{aligned}
& \text { Men and women } \\
& \mathrm{V}=-0.0086 \text { (A) }-0.006(\mathrm{PY})+1.25(\mathrm{P}<0.001, \mathrm{NS}) \\
& \mathrm{V}=-0.0089 \text { (A) }-0.0001(\mathrm{PPY})+1.26(\mathrm{P}<0.001, \mathrm{NS}) \\
& \text { Men } \\
& \mathrm{V}=-0.0100 \text { (A) }-0.0005 \text { (PY) }+1.34(\mathrm{P}<0.001, \mathrm{NS}) \\
& \mathrm{V}=-0.0115 \text { (A) }-0.0001 \text { (PPY) }+1.38(\mathrm{P}<0.001, \mathrm{NS}) \\
& \text { Women } \\
& \mathrm{V}=-0.0069 \text { (A) }-0.0001 \text { (PY) }+1.14(\mathrm{P}<0.001, \mathrm{NS}) \\
& \mathrm{V}=-0.0069 \text { (A) }-0.0001 \text { (PPY) }+1.14 \text { (P<0.001, NS) }
\end{aligned}
$$

Again, the effect of age was highly significant, but after allowance for this variable the contribution of cigarette exposure was negligible, whether measured in pack years or puff-pack years. Age coefficients for ex-smokers $(-0.0085 \pm 0.0020)$ and non-smokers $(-0.0099 \pm 0.0013)$ were very similar to those for the smokers.

\section{OVERT PATHOLOGY}

Of the 148 smokers 1 had an overt cataract and 1 'vitreous floaters'. None of the 96 ex-smokers or 182 non-smokers had diagnoses related to glaucoma.

\section{Discussion}

\section{TONOMETER PRESSURES}

The present report supports the observations of Bahna and Bjerkedahl (1948) in showing almost identical mean intraocular pressures for nonsmokers, ex-smokers, and smokers. However, the observations of Morgan and Drance (1975) are also substantiated in that (1) pressures are slightly higher in the small subgroup of subjects with a very high cigarette consumption, and (2) in women at least the multiple regression equation shows a significant effect of puff-pack years after allowance for the influence of age.

The average effect is of doubtful clinical signifi-

\footnotetext{
*Transformation of visual acuity into standard decimal format (e.g., $10 / 20=0.5$ ) is a necessary preliminary to calculation of the multiple regression.
}

cance (a pressure increment of about $0.27 \mathrm{kPa}$ $(2 \mathrm{mmHg})$ ), although in the worst case (consumption of 2 packs per day for 40 years, with 20 puffs per cigarette), the multiple regression equation suggests that the rise of pressure could amount to $2 \cdot 1 \mathrm{kPa}$ $(16 \mathrm{mmHg})$. The apparently larger effect on women is in keeping with their greater susceptibility to glaucoma (Armaly, 1965), and the correlation with puff-pack years but not pack years also suggests a true pharmacological effect. However, there was not a fixed period of abstinence from cigarettes either in the present study or in that of Morgan and Drance (1975), and the distribution of the increased pressures $(6 / 8<2.9 \mathrm{kPa}(22 \mathrm{mmHg}))$ supports the working hypothesis that we are seeing a transient response to recent smoking rather than a permanent elevation of pressure. This points the need for regulation of recent smoking when recording intraocular pressures. In the absence of such controls it is probably incorrect to regard as suffering from chronic uncomplicated glaucoma a patient who is a heavy smoker and has a pressure only a few millimetres of mercury above the average reading for non-smokers.

\section{VISUAL ACUITY}

The suggestion of a deterioration in visual acuity with an increase of cigarette consumption was not confirmed by our multiple regression analyses. We must conclude that neither the potential corneal irritation and lacrimation nor the threat of glaucoma has any effect on the ability to read standard clinical test type.

No great significance can be attached to the fact that the 1 case of overt cataract and the 1 case with vitreous floaters were both smokers. Since glaucoma develops only in about 1 patient in 200 over the age of 40 years (Armaly, 1965; Hollows and Graham, 1966; Bankes et al., 1968), a much larger sample would be needed to compare the incidence of pathological changes between smokers and nonsmokers.

We are much indebted to the following ophthalmologists for their co-operation in this project: Drs G. A. Thompson, R. K. MacDonald, F. Feldman, and H. Tanzer. The financial support of the York-Toronto TB and RD Association is also acknowledged with thanks.

\section{References}

Armaly, M. F. (1965). On the distribution of applanation tension. Archives of Ophthalmology, 73, 11.

Bahna, S. L., and Bjerkedahl, T. (1948). Smoking and intraocular pressure. American Journal of Ophthalmology, 31, 1597.

Ballantyne, B., Gazzard, M. F., and Swanston, D. W. (1977). Applanation tonometry in ophthalmic toxicology. In Current Approaches in Toxicology. Edited by B. Ballantyne. J. Wright: Bristol.

Ballantyne, B., and Swanston, D. W. (1977). The scope and 
limitation of acute eye irritation tests. In Current Approaches in toxicology. Edited by B. Ballantyne. J. Wright: Bristol.

Banks, J. L. K., Perkins, E. S., Tsolakis, S., and Wright, J. E. (1968). Bedford glaucoma survey. British Medical Journal, 1, 791.

Basu, J., Pimm, P., Shephard, R. J., and Silverman, F. (1978). The effect of cigarette smoke on the human tear film. Canadian Journal of Ophthalmology, 13, 22.

Duke-Elder, S., and Jay, B. (1969). Diseases of the lens and vitreous: Glaucoma and hypotony. In System of Ophthalmology, Vol. II. Edited by Sir Stewart Duke-Elder. Henry Kimpton: London.

Hollows, F. C., and Graham, P. A. (1966). Intraocular pressure, glaucoma and glaucoma suspects in a defined population. British Journal of Ophthalmology, 50, 570.

Mehra, K. S., Roy, P. N., and Khare, B. B. (1976). Tobacco smoking and glaucoma. Annals of Ophthalmology, 8, 462. Morgan, R. W., and Drance, S. M. (1975). Chronic openangle glaucoma and ocular hypertension. British Journal of Ophthalmology, 59, 211.

Non-Medical Use of Drugs Directorate (1976). Smoking habits of Canadians 1965-74. Health and Welfare. Ottawa, Ontario, Canada.

Sebben, J., Pimm, P., and Shephard, R. J. (1977). Cigarette smoke in enclosed public facilties. Archives of Environmental Health, March/April, p. 53.

Shephard, R. J., and LaBarre, R. (1978). Current attitudes towards smoking in Toronto. Canadian Journal of Public Health, 69, 121.

Shephard, R. J., Ponsford, E., Basu, K., and LaBarre, R. (1978). Effects of cigarette smoke on the eyes and airways. Canadian Journal of Public Health. Submitted for publication. 